\title{
DEHYDRATION IN THE ELDERLY: A REVIEW FOCUSED ON ECONOMIC BURDEN
}

\author{
M. FRANGESKOU' ${ }^{1}$, B. LOPEZ-VALCARCEL ${ }^{2}$, L. SERRA-MAJEM ${ }^{1,3}$
}

\begin{abstract}
1. Research Institute of Biomedical and Health Sciencies, University of Las Palmas de Gran Canaria, Las Palmas de Gran Canaria, Spain; 2. Department of Quantitative Methods in

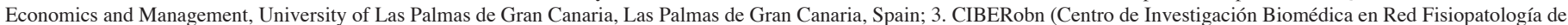

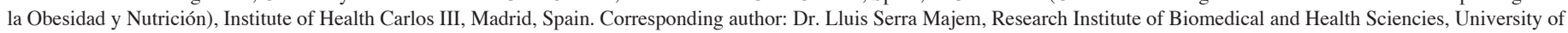
Las Palmas de Gran Canaria, PO Box 550; 35080-Las Palmas de Gran Canaria, Spain. Telephone:+34 928453476 Fax:+34 928453475 E-mail address: 1luis.serra@ulpgc.es
\end{abstract}

\begin{abstract}
Background: Dehydration is the most common fluid and electrolyte problem among elderly patients. It is reported to be widely prevalent and costly to individuals and to the health care system. The purpose of this review is to summarize the literature on the economic burden of dehydration in the elderly. Method: A comprehensive search of several databases from database inception to November 2013, only in English language, was conducted. The databases included Pubmed and ISI Web of Science. The search terms «dehydration»/ "hyponaremia" / "hypernatremia" AND «cost» AND «elderly» were used to search for comparative studies of the economic burden of dehydration. A total of 15 papers were identified. Results: Dehydration in the elderly is an independent factor of higher health care expenditures. It is directly associated with an increase in hospital mortality, as well as with an increase in the utilization of ICU, short and long term care facilities, readmission rates and hospital resources, especially among those with moderate to severe hyponatremia. Conclusions: Dehydration represents a potential target for intervention to reduce healthcare expenditures and improve patients' quality of life.
\end{abstract}

Key words: Dehydration, economic costs, hospitalized patients, elderly.

\section{Introduction}

Declining birth rates and increased life expectancy have substantially raised the proportion of elderly people in the population and the total number of older people around the world and these trends are expected to continue (1). Worldwide, those aged 60 years and over are the fastest growing segment of the population and those over 80 years are the fastest growing group (1).

The elderly population has a high rate of chronic illness (2) and is more vulnerable to disease. People aged 65 and over have more hospital stays than any other group. Ageing populations will therefore place even greater demands on social and health services around the world (1).

Dehydration is the most common electrolyte disorder among elderly patients. It is widely prevalent and costly to individuals and to the health care system (3). According to U. S. statistics, \$1.36 billion was spent in 1996 to treat hospitalized elderly patients with dehydration as their primary diagnosis (4). Particularly dehydration often leads to poor health and medical outcomes; increased hospitalization, and increased usage of long term care (LTC) facilities. It is associated with significantly longer stays in rehabilitation settings and contributes to the development of chronic diseases (5). Therefore because of its high incidence of cases among the elderly, small increases in its prevalence can translate to substantial impacts at the population-level. The present article is a review of the literature of dehydration among the hospitalized elderly population, with a main focus on economic burden.

\section{Methods}

\section{Search strategies}

A comprehensive search of several databases from database inception to November 2013, only in English language, was conducted. The databases included Pubmed and ISI Web of Science. The search terms «dehydration»/"hyponaremia" / "hypernatremia" AND «cost» AND «elderly» were used to search for comparative studies of the economic burden of dehydration.

\section{Study selection}

We considered all the empirical studies published in English language that evaluated the effect of dehydration on hospital outcomes of elderly patients diagnosed with dehydration. Studies were eligible if their cohort of patients had a mean age $>60$ and if they reported medical outcomes other than mortality. They were reviewed and rated based on their relevance to cost of illness and the reliability of the estimates. Initial abstract screening excluded non-relevant studies or non-original studies. Full-text screening was then performed to assess eligibility. The total number of articles retrieved was 126. After a filtering process based on the text of the abstract, we kept 15 studies. Study characteristics and reported outcomes are described in Table 1.

Furthermore depression and loneliness usually observed in elderly patients have been identified as major contributors to inadequate fluid intake in hospital and nursing elderly residents. Term depression reflects symptoms such as sadness, lack of motivation, social isolation, and hopelessness (6). 


\section{DEHYDRATION IN THE ELDERLY: A REVIEW FOCUSED ON ECONOMIC BURDEN}

\section{Dehydration as a medical problem}

Dehydration in clinical practice, and especially long term care, is most often functionally considered as a loss of total body water content due to pathologic fluid losses, diminished fluid intake or a combination of both (7). However it is important to understand and distinguish the body's three forms of water depletion; hypertonic, isotonic and hypotonic (different serum sodium levels) (8) in order to address and underline the causes in a timely and appropriate manner.

Many studies looking at the clinical outcomes of dehydration have shown that decreased fluid intake has a direct impact on individuals' health status. Dehydration has been proved to be a major risk factor in the development of many diseases such as stone disease $(9,10)$ or it appears as a comorbid condition of multiple diseases such as mitral valve prolapse and salivary dysfunction $(11,12)$ certain types of cancers $(12-14)$, pulmonary diseases (15), heat failure (16), physical impairment (17-21) contributing to their deterioration (22)

Dehydration is not only widespread among the elderly, but also an independent predictor of mortality. A number of studies have reported mortality rates associated with hypernatremia greater than $40 \%$ (23-25) and are commonly related to the underlying disease processes $(24,25)$. In a cohort of 4123 elderly patients, Terzian et al (26) studied the relationship between hyponatremia at the time of hospital admission and treatment outcomes. After controlling for different confounders hyponatremia was a significant independent predictor of mortality. In more recent studies such as the one by Wald et al. (27) patients diagnosed with hyponatremia $(<135 \mathrm{mmo} / \mathrm{L})$ had a risk of in-hospital mortality as high as $47 \%$, and that risk was doubled for patients with a serum sodium concentration between 125 and $129 \mathrm{mmo} / \mathrm{L}$.

Increasing age is a strong independent risk factor for both hypo- and hypernatremia (28). The concept of progressive intermittent frailty almost ensures that the elderly will go through periods of illness with associated dehydration (29). The reasons of elderly being exposed to higher risk of dehydration are well known and documented in the literature.

Firstly water and salt homeostasis are affected by a variety of age related factors $(30,31)$. As one ages, there is less total body water due to a decrease in lean body mass and an increase in percentage of body fat $(32,33)$. Moreover kidneys of elderly people present structural as well functional changes $(34,35)$ leading to the development of hyponatremia. Hyponatremia in turn increases the risk of other illnesses (e.g. disorientation, coma etc.) (36).

In addition thirst sensation is lessened with age (32). Findings consistently support the conclusion that the elderly do not feel as thirsty as younger persons following water deprivation and subsequently do not drink enough to rehydrate themselves $(7,37)$. Many elderly may also intentionally reduce their fluid intake to reduce incontinence, which has been found as a risk factor for significantly lower fluid intake for avoiding humiliation $(38,39)$.

\section{Figure 1}

Economic Burden of Dehydration

\begin{tabular}{|c|c|}
\hline \multicolumn{2}{|c|}{ Economic Burden of Dehydration } \\
\hline $\begin{array}{l}\text { Direct Way } \\
\text { Dehydration as a } \\
\text { primary diagnosis } \\
\downarrow \\
\text { Direct Costs } \\
(+)^{1} \text { Hospitalizations with a } \\
\text { primary diagnosis of } \\
\text { dehydration }\end{array}$ & 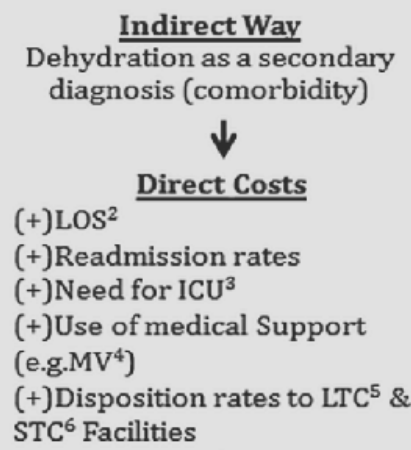 \\
\hline $\begin{array}{l}\text { Lndirect Cost } \\
\begin{array}{l}(+) \text { Time } \\
\text { caregive } \\
(+) \text { Incon } \\
\text { member }\end{array}\end{array}$ & $\begin{array}{l}\text { ductivity lost by patients and } \\
\text { y patients and family }\end{array}$ \\
\hline
\end{tabular}

1. Increase/ 2. Length of Stay/ 3. Intensive Care Unit/ 4. Mechanical Ventilation/ 5. Long Term Care/ 6. Short Term Care

\section{Dehydration in the elderly}

Another factor that contributes to the prevalence of dehydration in elderly people is their higher rate of chronic illness (2) which can disrupt the body's ability to balance and manage fluids and electrolytes $(40,41)$. For example persons with diabetes (42) or neurological and neurosurgical diseases are $(8,43,44)$, cognitively impairment $(40)$ are particularly at risk for dehydration. However the relationship of delirium and dehydration is complex, because each may contribute to the other in a vicious cycle. Some elderly people simply do not know how much fluid they need or do not remember to ask for it because they are cognitively impaired (40) but dehydration can itself contribute to impaired mental function, which may then make the sufferer forget to drink, and so on (8).

Moreover, multiple diseases such as cardiac glycosides (45), furosemide (24), laxatives (46), and dilating suppresses vasopressin release (32) usually found in elderly are combined with intensive drug consumption which not surprisingly has untoward side effects on water and electrolyte balances of individuals. Additionally dehydration has also been associated with malnutrition (47), resulting in reduction of secondary thirst as food consumption declines. Another hypothesis suggests that aging is associated with changes in satiation that hinder adequate rehydration in response to hyperosmolarity (48) and swallowing difficulty (6).

Finally depression and loneliness usually observed in elderly patients (especially in nursing home patients) have been identified as major contributors to inadequate fluid intake in 


\section{JNHA: NUTRITION}

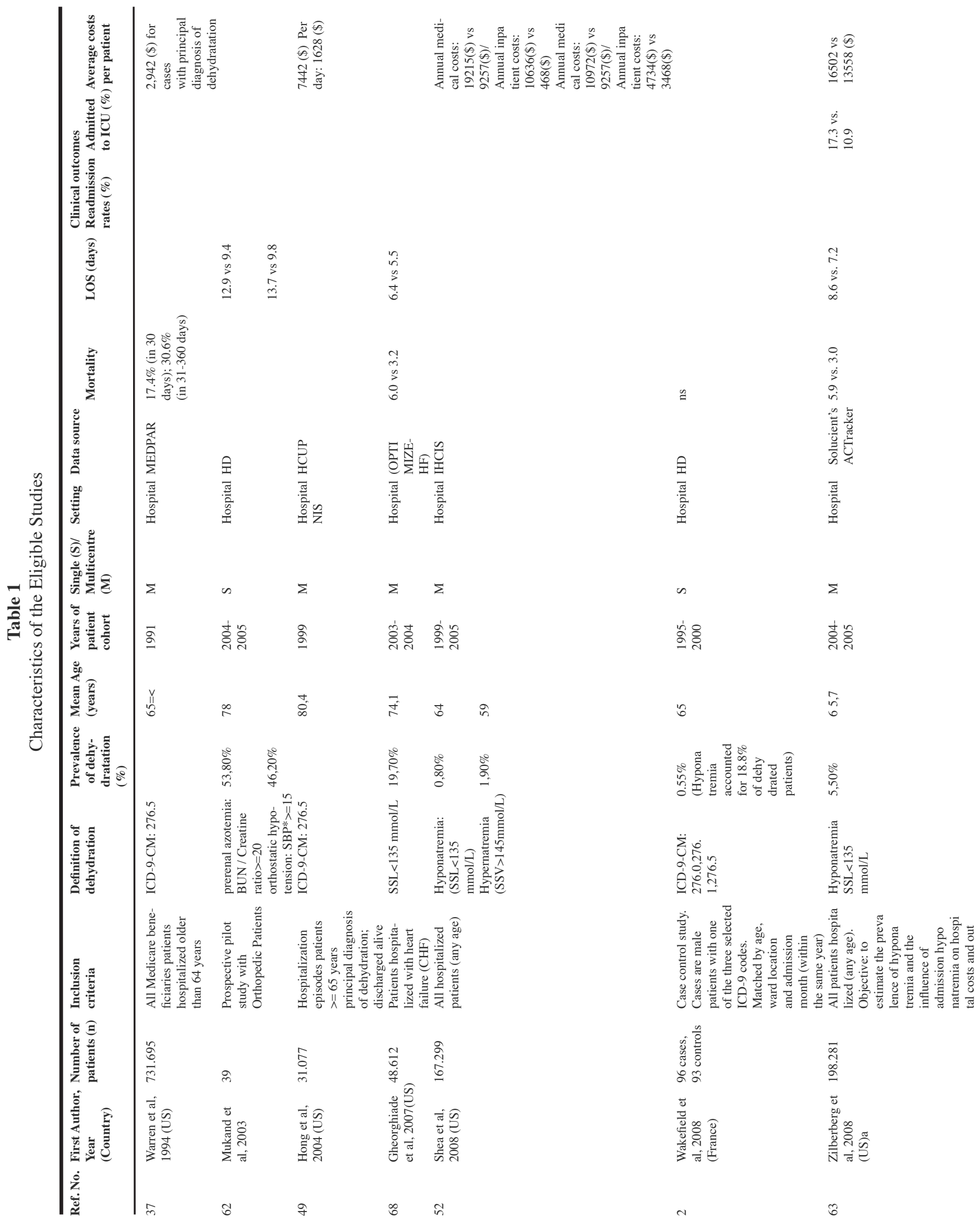




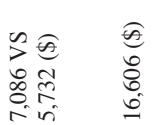

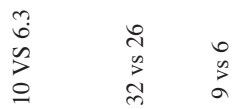$$
\begin{array}{ll}
0 & \\
i & \\
0 & 0 \\
i & 0 \\
0 & \infty \\
r & \infty
\end{array}
$$

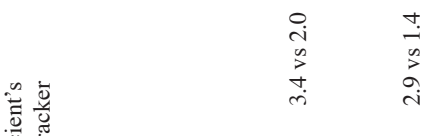

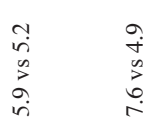

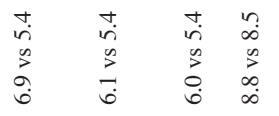$$
\begin{array}{lll}
\vec{i} & \vec{i} & \vec{i} \\
0 & \vec{z} & \vec{z} \\
0 & a & \hat{\sigma}
\end{array}
$$<smiles>[CH]1[CH]C1</smiles>

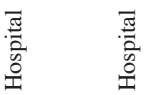

$$
\text { 旺 }
$$$$
\text { : }
$$

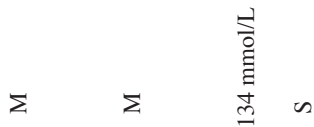

ठั่

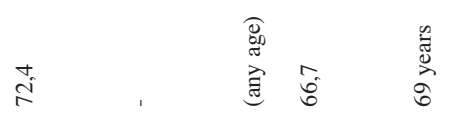

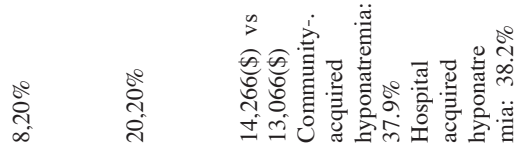

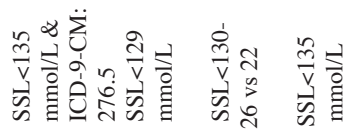
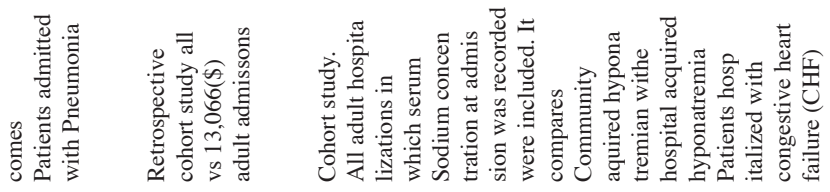

$\Sigma$

¿ำ

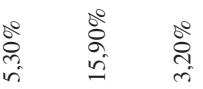

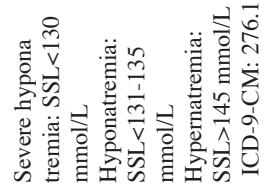

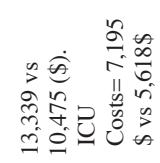

$\stackrel{0}{n}$
$\infty$
$\dot{\sim}$
$\dot{\sim}$<smiles>c1ccccc1</smiles>

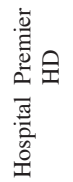

휴을

훙ㅎㅀ

¿্ণ

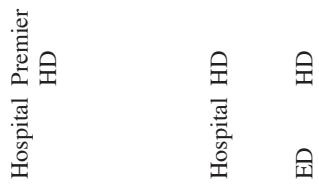

$\Sigma$
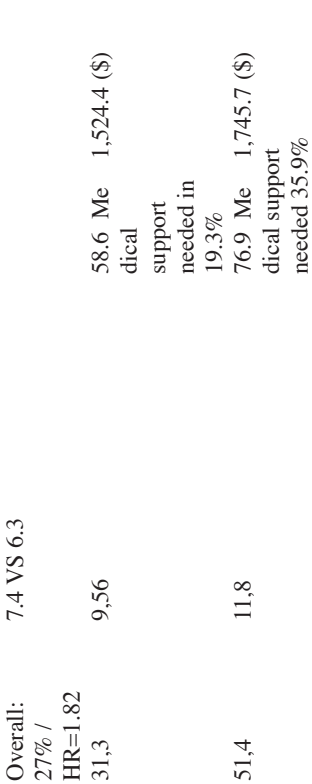

列
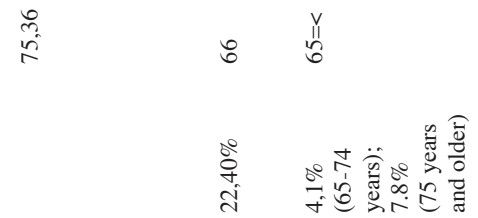

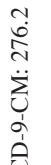

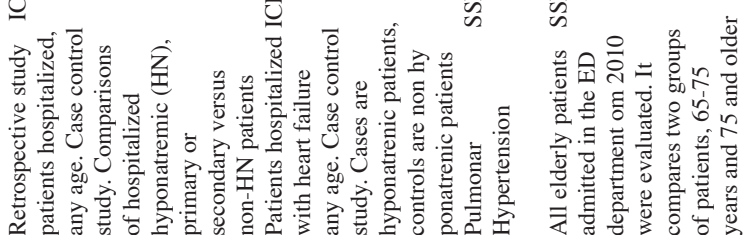

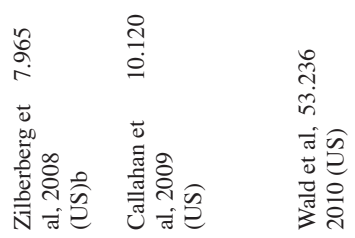

ఏे
ำ

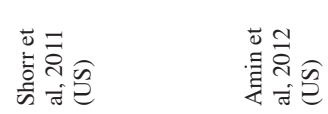

$\widehat{6}$

in

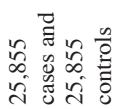

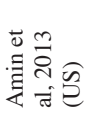

हิ ते

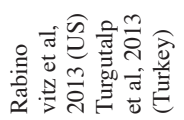

ㄱำ

ง

8

8 in

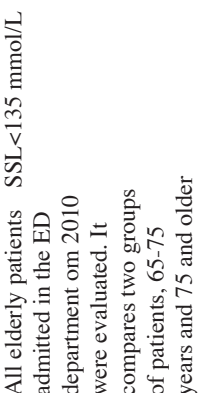

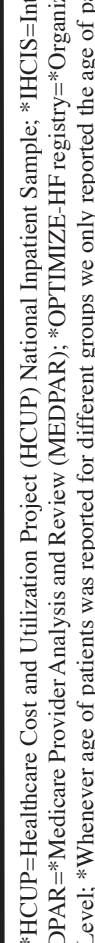




\section{JNHA: NUTRITION}

hospital and nursing elderly residents. Term depression reflects symptoms such as sadness, lack of motivation, social isolation, and hopelessness (8).

\section{Prevalence of Dehydration among elderly}

The evidence of dehydration among the elderly is well known and documented $(49,50)$. Dehydration affects a large number of elderly persons (51) and cases can only be expected to increase as the elderly come to make up an even larger segment of the population. Haveman-Nies et al (51) studied the fluid intake of elderly Europeans and found that fluid intake of elderly people varied between the towns of Europe and between men and women. A high percentage of the female population had a water intake below the cut-off value. Patients diagnosed with hyponatremia were more likely to be female in most of the studies $(49,52,53)$.

Increasing age was a major factor in risk of admission with dehydration in most of the studies. For example Hong et al (49) using hospital discharge data from the Health Care Cost and Utilization Project (HCUP), found that more than half of the hospitalizations involving a principal diagnosis of dehydration were for individuals of at least 65 years of age. Warren et al (37) reported that patients 85 to 99 years of age were 6 times more likely to be hospitalized for dehydration than those 65 to 69 years of age. Similarly Curtze et al (54) found that hospitalization-required hyponatremia is more common in very elderly persons than in elderly (Table 1).

Furthermore hyponatremia has been reported to be almost $20 \%$ in older adults presenting to the emergency department (ED) (55) and it has also been observed in many hospital admissions of nursing home residents (8). Few older studies available on the prevalence of dehydration among the elderly suggested that those living in LTC facilities were twice as likely to be dehydrated (22\%) as the acutely ill hospitalized elderly $(11 \%)(56)$. More recent studies confirm these findings. Mentes et al (57) found that dehydration events occurred in $31 \%$ of residents over 6 months and in two other studies, $34 \%$ of nursing home patients admitted to hospital were diagnosed with dehydration (39) and $84 \%$ of hypernatraemic patients developed this during admission to hospital while $16 \%$ were hypernatraemic on admission (23).

\section{Economic Consequences}

\section{Enumeration of effects}

Although the clinical consequences of dehydration in elderly are well documented, relatively little is known about the relationship between dehydration and medical costs. Hyponatremia among hospitalized and community elderly patients carries important clinical and economic implications. Whether it is present on admission, exacerbated after admission, or develops during hospitalization, it imparts a considerable burden on the consumption of healthcare resources $(52,58)$. It contributes to an increase in hospitalizations $(37,49)$, admission to ICU $(27,58-60)$, readmission to the hospital (58) and dispositions to long term or short term care facilities $(27,61)$. It is evident that all these factors increase hospital costs through the increase in usage of hospital equipment, drugs, medical tests and procedures (59, $62,63)$, need for hospital staff; doctors, nurses etc.

\section{Cost types to be considered, sources and measures (direct and indirect costs)}

Dehydration substantially increases the health care burden in a direct way, as a disease itself, or an indirect way as comorbidity of another disease. For example hospitalizations for dehydration can be assumed to be a direct predictor of healthcare costs. The number of hospitalizations for dehydration has steadily increased in recent decades. Specifically over the decade of 1990-2000 the rate of dehydration related hospitalizations in the US increased by $40.4 \%$ (64). Many studies reported high rates of hospitalizations for dehydration among the elderly population $(37,49)$. For example Warren et al $(37)$ reported that the rate of hospitalizations per 10000 elderly was 236.2 admissions with any listed diagnosis of dehydration and 49.7 admissions for dehydration as the principal diagnosis.

Additionally dehydration leads to the development of other diseases, which lead to hospitalizations and are directly related to an increase of healthcare costs. Indeed Zilberberg et al (63) found that hyponatremic patients have a higher co-morbidity index than patients with normal serum sodium. There is no doubt that these co-morbidities contribute to the need for emergency departments and an increase in length of stay (LOS) (59).

Although dehydration is a disease itself it is also appeared as comorbidity condition in a number of diseases. According to an AHRQ study of the 1997 Nationwide Inpatient Sample (NIS) (65) representing all patients in acute care hospitals, dehydration was diagnosed more commonly as comorbidity than as a principal diagnosis. Dehydration was the second most common comorbidity, occurring in $14 \%$ of all hospitalizations (64). Thus, dehydration may contribute to the increase of medical costs in an indirect way. It may be a marker of the severity of the underlying disease or it may add its own complications to those of the underlying disorder (63). For instance Chinet al, performed a retrospective study of 435 patients admitted to a university hospital performing a multivariate analysis of these patients and found that the serum $[\mathrm{Na}+]<135 \mathrm{mmo} / \mathrm{l}$ was a significant and independent predictor $(\mathrm{p}<0.01)$ of major complications in a patient's health status (66)

There is a wide range of studies in the literature analyzing and reporting the effect of dehydration as a comorbidity disease on the clinical and medical outcomes of different elderly patient such as orthopedic (61), with heart failure (60, $67,68)$, pulmonary diseases $(62,69)$ and many others. For example Mukand et al, (61)and Zilberberg et al (62) in their studies found that dehydration prolongs length of stay for 


\section{DEHYDRATION IN THE ELDERLY: A REVIEW FOCUSED ON ECONOMIC BURDEN}

patients admitted with orthopedic and pneumonia respectively. Additionally Rabinovitz et al (69) found that hyponatremic patients had longer length of stay but also higher rate of hospital readmission.

In addition dehydration causes fluid deficits within cells which can affect the absorption of medications and averts drugs' expected effects. Therefore compromises optimal treatment of the underlying disorder (4) causing prolongation of treatment effects. Chronic disease and disorders, and multidrug therapy related to these conditions are common in elderly persons (70). Salmon (18) in his study pointed out that patients with dehydration have more difficulties in absorbing the medication for some diseases they face leading to a retardation of their healing.

Dehydration thus acts as an independent factor in the increase of the duration of hospitalization $(27,52,58,60-63$, $66,68,69,71)$; hospital readmission rate $(58,60)$, the need for intensive care $(27,58-60)$ : use of medical support $(52,59)$ and the disposition to long or short term facility $(27,61)$. This is simply because dehydrated patients represent a sicker cohort among all those with the underlying disorder. These types of costs can be assumed as direct costs incurred by dehydration (Figure 1).

However there is no doubt that the indirect costs of hyponatremia such as time and productivity loss by patients and caregivers because of the illness as well as income lost by patients and family members, pose a substantial burden on households (Figure 1). However, as far as we know, no study has been conducted estimating these types of costs.

\section{Overview of the methods for calculating costs}

The studies found in the literature reflect the diversity of methods used to assess the economic burden from dehydration in the society. The methodological differences in the studies inherently prevent a formal meta-analysis from being performed. A discussion on the different methodologies used follows:

Firstly there is diversification among the studies in the definition of dehydration. Some studies define hospitalization for dehydration with the code ICD-9-CM or ICD-10-CM (International Classification of Diseases, Ninth Revision, Clinical Modification) as recorded in national database (2, $37,49,58,60)$. For example Wakefield et al (2) in their study as a case they defined a patient with one of three ICD-9-CM codes as the principal diagnosis (i.e., reason for admission). The three principal diagnoses ICD-9-CM were hyperosmolality or hypernatremia, hypo-osmolality or hyponatremia; and volume depletion (22). While in other studies, where data are available authors define dehydration according to the serum sodium level of the hospitalized patients $(27,52,59$, $61-63,67-69,71)$ and even more they assessed the impact of different levels of dehydration on paients' outcome $(52,59$, 67). For instance Turgutalp et al (59) looked on the severity of the disease. They separated their patients according to their level of hyponatremia, depending on serum $\mathrm{Na}$ level; mild hyponatremia $(130 \mathrm{mmo} / \mathrm{l}<\mathrm{Na}+<135 \mathrm{mmo} / \mathrm{l})$, moderate hyponatremia $(120 \mathrm{mmo} / \mathrm{l}<\mathrm{Na}+<130 \mathrm{mmo} / \mathrm{l})$ and severe hyponatremia $(\mathrm{Na}+<120 \mathrm{mmo} / \mathrm{l})$. However, most authors study only the economic effects of hyponatremia assuming that it is the most common type of dehydration $(58,60)$. Additionally there are some authors who used indices of dehydration such as BUN/Creatine ratio and systolic blood pressure (61).

Secondly the studies differ in the outcomes of measure. Some studies look only on hospital admission costs $(37,49)$ of dehydration while others look on hospital $(27,58-63,67-69$, 71 ) or (ICU) length of stay (LOS) $(58,60,62)$, intensive care unit (ICU) costs of admission $(58,60)$, hospital readmission rates $(58,60)$, admission to ICU $(59,61-63)$, need of medical support (MV) $(59,62,63)$ as well as disposition to short or long term care facilities $(27,61)$; all of which are drivers of costs.

Diversity in the definition of outcomes has also been observed. For example some studies look only on the cost of hospitalizations with a principal diagnosis of dehydration (37, 49). Data limitations prevent those studies to look on the cost of dehydration as a comorbidity condition. Hong (49) and Warren et al (37) conservatively estimate the economic burden associated with avoidable hospitalizations for dehydration by assuming equivalency between hospital charges and costs. Whereas authors, where data allow them, calculate total medical costs by summing the given standardized cost values for all hyponatremic patients found in inpatient facilities, outpatient facilities, professional services, and ambulatory services incurred in their study period (52).

Thirdly studies differ in their group of patients. A number of studies look on the impact of dehydration as a primary or secondary diagnosis of hospitalizations $(27,37,49,52,58,63$, 71) while other studies look on its impact on a specific group of patients such as patients with heart failure $(60,67,68)$, pulmonary diseases $(62,69)$ and orthopaedic $(61)$.

Moreover studies differ in their setting of study. Although in many studies the sample of study was comprised from all the patients admitted in the hospital, some authors study a specific group of hospitalized patients (e.g. Emergency department, ICU etc). Turgutalp et al (59) for example estimated the clinical features, outcomes and costs of patients admitted to the emergency department (ED) and were identified with hyponatremia . While Mukand et al (61) looked only on patients who took surgery, therefore on surgical department.

It also worth mentioning that a number of studies look on only on patients admitted to a single centre $(2,27,59,61,69)$ while other studies which mainly use data from databases with a sample of hospitals, multicentre $(37,49,52,58,60,62,63$, $67,68,71)$. A factor that directly affected their findings.

Finally the studies differ in their design and statistical analysis. Economic evaluations of dehydration have been done in different ways by different researchers; most of them performed retrospective studies using already collected longitudinal retrospective data of elderly patients hospitalized 


\section{JNHA: NUTRITION}

in different academic and non-academic hospitals $(2,27,37$, $49,52,58-60,62,63,67-69,71)$. In contrast Mukand et al (61) performed a prospective, pilot study, where the subjects were patients who had surgery for orthopaedic reasonsAlthough the methodologies and hence the numerical results of these studies vary, all of them send a message for the proper management of the hydration status of patients, early detection and prevention so as to avoid an unnecessary increase in medical costs.

Review of the evidence on the economic burden of dehydration in elderly people

All of the studies reviewed assessed direct costs of dehydration disease, which include all the costs incurred by hospitalized patients. The numerical results of those studies vary because of the differences between the studies, mentioned above. In this section we present evidence on these direct costs.

Warren et al (37) found out that dehydration was 1 of 10 most frequent diagnoses reported for hospitalizations of persons over 65 and accounted for Medicare reimbursement to hospitals in excess of $\$ 446$ million for a single year. Zilberberg et al (63) estimated \$2289 to \$3480 rise in total hospital costs for each day for each patient hospitalized with hyponatremia. However, Shea et al (52) found that 1-yr mean inpatient costs for patients with hyponatremia were approximately $\$ 10,636$, more than 3 times higher than the previous estimate of Zilberberg et al (63). In their study, inpatient costs accounted for just over half of all direct medical costs.

In addition in their comparison of the hospital costs between hyponatremic and non-hyponatremic patients most of the authors found significant differences $(58-60,62,63,71)$. For example Callahan et al (71) found that patients with hyponatremia cost $14266 \$$ per admission compared to the nonhyponatremic patients which cost 13066 . Similarly Zilberberg et al (63) found almost $3000 \$$ difference between the two groups.

Furthermore, increases in length of stay (LOS) due to the negative effects of hyponatremia on the health of patients have been shown by a number of authors $(27,52,58,60-63,66$, $68,69,71)$. The difference in hospital LOS at first admission between $\mathrm{HN}$ and non-HN patients in the study Amin et al (58) was 1.1 days. Similar to that reported in a study conducted by Shorr et al (67) which found a 0.7 and 1.28 day greater LOS for $\mathrm{HN}$ and severe HN HF patients, respectively, in comparison with non hyponatremic HF patients]. Zilberberg (63) and Callahan et al (71) performing retrospective cohort analyses and making the same comparison reported a difference of 1.4 days and 2.0 days respectively.

Patients diagnosed with hyponatremia are significantly more likely to be readmitted to hospital for any cause than patients with similar demographics and characteristics who do not have hyponatremia $(58,60)$. Hospital readmissions are a significant contributor to total healthcare costs, with some being entirely avoidable with increased standards of care. Gheorgheade et al (68) in their studies which were conducted on clinical trial patients with acute heart failure found that HN patients in comparison to non-HN patients reported a significant increase in readmission rates. However, Amin et al (60) reported that hyponatremia was associated with an incremental increase ranging between $14 \%$ and $17 \%$ for hospital readmission for any cause.

Zilberberg (63) and Callahan et al (71) reported that HN patients had a significantly greater need for ICU $(4 \%-10 \%)$. Hyponatremia is a very relevant electrolyte disorder among people who report to the emergency department (ED). Focusing on ICU population Zilberberg et al (63) found out that hyponatremia was twice as frequent as in the overall hospital population $(11.3 \%)$ and its independent association to worsened outcomes persisted. For example, hyponatremic ICU patients were significantly more likely to experience such dire clinical outcome as hospital death, as well as to require mechanical ventilation. With an average adjusted cost of MV of $\$ 1,500$ per day, this increased utilization is likely to add substantially to the overall costs of care. Similarly Turgutalp et al (59) in their study reported positive relationship between the age and the need for intensive care and ventilator support. Amin et al (58) in their sudy estimated ICU costs per admission and found that hyponatremic patients costs approximately $1600 \$$ more than non-hyponatremic patients.

Severity of hyponatremia prognosticates adverse outcomes, especially when hyponatremia develops in hospital. According to Wald et al (27) patients with hospital acquired hyponatremia have higher risk of death compared to the community acquired hyponatremia. Moreover patients with hospital acquired hyponatremia were shown to be frequently associated with delays in the imitation of treatment.

At aggregate level, the potential national saving from avoidable hospitalizations in elderly patients (older than 65) hospitalized for dehydratation has been estimated in $\$ 1,14$ billion for 1999 (49).

\section{Final considerations}

This literature review has presented the available evidence on the economic burden related to dehydration. However before concluding its most important results, some of the methodological issues in many of the studies that were included will be highlighted. First, in most retrospective cohort studies the prevalence of hyponatremia illness was based in large part on the number of hospitalizations with the code ICD-9-CM or ICD-10-CM as recorded in a national database $(49,58,60,62$, $63,72)$. There was evidence that these codes for hyponatremia represent only a low proportion of the patients admitted to the hospital and were experiencing hyponatremia, due to the low sensitivity of the diagnosis code (73). Moreover, a high proportion of hyponatremia in the hospital setting is iatrogenic and hospitals may be reluctant to include the code in the discharge data. Any retrospective analysis may have thus faced the same study limitations (73). 


\section{DEHYDRATION IN THE ELDERLY: A REVIEW FOCUSED ON ECONOMIC BURDEN}

Second, the studies which used individual comorbidity indexes mainly used administrative codes. This is relatively crude and does not account for the severity of the condition in question. Therefore the inability to incorporate the severity of the comorbidities might have led to some unmeasured confounding in the analysis. The substantial variations in study designs and definitions described earlier also make comparisons tricky and meta-analysis infeasible. There is considerable heterogeneity in methodologies used in the papers.

Taking into consideration the methodological issues highlighted here we can still conclude that dehydration already imposes substantial financial costs in the society. According to the degree or magnitude of the dehydration in hospitalized patients increase costs by $7 \%$ to $8.5 \%$. Higher cost will be associated with an increase in hospital mortality, as well as with an increase in the utilization of ICU, short and long term care facilities, readmission rates and hospital resources, especially among those with moderate to severe hyponatremia. The more severe the level of hyponatremia, the more likely a patient's hospitalization will be prolonged $(27,71)$. Data available from both the US (74) and Europe (75) show that mortality and medical costs are reduced by effective treatment of hyponatremia $(58,60,62,63,67,68)$. However, most of the research is only based on directs costs of dehydration. Therefore future research needs to be done in estimating indirect costs associated with it in order to have a more complete picture of its economic burden.

Dehydration as a syndrome cannot be treated merely by throwing water at it! Surveys should look not at its mere sentinel presence, but whether it was addressed in a multifaceted method that accounts for underlying cause(s), considers pharmacology involved, reviews the involvement of the physician and staff, addresses moral principles that arise, and places it in the context of individual circumstances. We need a better reality in long term care that addresses education regarding modern thoughts about dehydration, the importance of careful clinical approaches, the concept of unavoidability, and the need to reconsider how we survey this complex entity. Patients' admission and discharge statistics should accurately include the diagnosis of dehydration as a comorbidity or main disease, in order to help to patient management and to allow appropriate research and comparisons across centres.

Rapid recognition and optimal treatment of depressed serum sodium or osmorality can reduce the risk of death and symptom severity, permit less intensive care, reduce the duration of hospitalization and associated costs, increase success in treatment of underlying comorbid conditions, and improve quality of life. This implies a healthier and automatically more productive population. In their studies Licata (76) and Leadbetter et al (77) have shown that treatment of hyponatremia and dehydration reduces the frequency and severity of many side effects. These benefits relieve patients from mental and economic costs, increasing their quality of life.
Conflict of interests: This review was supported through a research grant from the European Hydration Institute (EHI) allocated to the Fundación Universitaria de Las Palmas. None of the authors declare any conflict of interest. Dr. Serra-Majem serves as a member of the Scientific Committee of the EHI but did not participate in the process of research grant selection and allocation. The authors acknowledge the support from the EHI.

\section{References}

1. WHO (World Health Organization) Health and ageing. 2002.

2. Wakefield BJ, Mentes J, Holman JE, Culp K. Risk factors and outcomes associated with hospital admission for dehydration. Rehabil Nurs [Internet]. 2008;33(6):233-41. Available from: http://www.ncbi.nlm.nih.gov/pubmed/19024237

3. Begum MN, Johnson CS. A review of the literature on dehydration in the institutionalized elderly. E Spen Eur E J Clin Nutr Metab [Internet]. Elsevier Ltd; 2010 Feb [cited 2014 Jun 4];5(1):e47-e53. Available from: http://linkinghub. elsevier.com/retrieve/pii/S1751499109000936

4. Kayser-Jones J, Schell ES, Porter C, Barbaccia JC, Shaw H. Factors contributing to dehydration in nursing homes: inadequate staffing and lack of professional supervision. [Internet]. Journal of the American Geriatrics Society. 1999. p. 1187-94. Available from: http://www.ncbi.nlm.nih.gov/pubmed/10522951

5. Himmelstein DU, Jones AA WS. Hypernatremic dehydration in nursing home patients: An indicator of neglect. J Am Geriatr Soc. 1983;31(8):466-71.

6. JC M. Oral hydration in older adults: greater awareness is needed in preventing, recognizing, and treating dehydration. Am J Nurs. 106:40-9.

7. Gross CR, Lindquist RD, Woolley AC, Granieri R, Allard K WB. Clinical indicators of dehydration severity in elderly patients. J Emerg Med. 1992;10(3):267-74.

8. Mentes JC, Chang BL, Morris J. Keeping nursing home residents hydrated. West J Nurs Res [Internet]. 2006 Jun [cited 2014 Jun 4];28(4):392-406; discussion 407-18. Available from: http://www.ncbi.nlm.nih.gov/pubmed/16672630

9. Borghi L, Meschi T, Amato F, Briganti A, Novarini A GA. Urinary Volume, water and recurrences in idiopathic calcium nephrolithiasis: a 5-year randomized prospective study. Urology. 1996;155:839-43.

10. Hughes J NR. Diet and calcium stones. Cab Ned Assoc J. 1992;146:137-43.

11. Lax D, Eicher M GS. Mild dehydration induces echocardiographic signs of mitral valve prolapse in healthy females with prior normal cardiac findings. Am Hear J. 1992;124(6):1533-40.

12. Ship JA FD. The relationship between dehydration and parotid salivary gland function in yong and older healthy adults. J Gerontol. 1997;52A:M310-M319.

13. Bitterman WA, Faarhadian H, Abu S-C, Lerner D, Amoun H, Krapf D MU. Environment and nutritional factors significantly associated with cancer of the urinary tract among different ethnic groups. Urol Clin North Am. 1991;18:501-18.

14. Wilkens LR, Kadir MM, Kolonel LN, Nomura AM HJ. Risk factors for lower urinary tract cancer: the role of total fluid consumption, nitrites and nitrosamines, and selected foods. Cancer Epidemiol, Biomarkers Prev. 1996;5:161-6.

15. Asadollahi K, Beeching N G. Hyponatraemia as a risk factor for hospital mortality. Q J Med. 2006;99:877-80.

16. Centers for Disease Control and Prevention. Heart failure fact sheet. Accessed November 12, 2013 [Internet]. Available from: http://www.cdc.gov /DHDSP/data_ statistics/fact_sheets/fs_heart_failure.htm.

17. M F. Confusion in hospitalized elderly: Incidence, onset and associated factors. Res Nurs Health. 1989;12:21-9.

18. Salmon P. Nutrition cognitive performance, and mental fatigue». Nutrition. 1994;10:427-8.

19. LM B. Fluid balance during team sports. J Sport Sci. 1997;15:287-95.

20. Suhr JA, Hall J, Patterson SM NR. The relation of hydration status to cognitive performance in healthy older adults. Int J Psychophysiol. 2004;53:121-5.

21. Wilson MM MJ. Impaired cognitive function and mental performance in mild dehydration. Eur J Clin Nutr. 2003;57(2):24-9.

22. Weinberg A.D., Pals J.K., McGlinchey-Berroth R. MKL. Indices of dehydration among frail nursing home patients: highly variable but stable over time. J Am Geriatr Soc. 1994;42:1070-3.

23. Palevsky PM, Bhagrath R GA. Hypernatremia in hospitalized patients. Ann Intern Med,. 1996;124:197-203.

24. Snyder A, Fiegal DW AA. Hypernatremia in elderly patients: a heterogeneous, morbid, and iatrogenic entity. Ann Intern Med. 1987;107:309-19.

25. J Am Geriar Soc. Clinical presentation of hypernatremia in elderly patients. A case control study. Chass P, Druesne L, Capet C, Menard JF, Bercoff E. 2006;56:122530 .

26. Terzian C, Frye EB PZ. Admission hyponatremia in the elderly: factors influencing prognosis. J Gen Intern Med. 1994;9:89-91.

27. Wald R, Jaber BL, Price LL, Upadhyay A, Madias NE. Impact of hospitalassociated hyponatremia on selected outcomes. Arch Intern Med [Internet]. $2010 \mathrm{Feb}$ 8;170(3):294-302. Available from: http://www.ncbi.nlm.nih.gov/pubmed/20142578

28. RC H. Age and gender as risk factors for hyponatremia and hypernatremia. Dep Pathol Lab Med. 2003;337(1-2):169-72.

29. Lynn J AD. Living well at end of life: adapting health care to serious chronic illness in old age. Rand Heal White Pap. 2003;137. 


\section{JNHA: NUTRITION}

30. Davies I, O'Neill P MK. Age-associated alterations in thirst and arginine vasopressin in response to a water or sodium load. Age Ageing. 1995;24:151-9.

31. Lindeman RD, Tobin J SN. Longitudinal studies on the rate of decline in renal function with age. J Am Geriatr Soc. 1985;33:278-85.

32. Davis KM MK. Disorders of fluid balance. In: Hazard W. Principles of Geriatric Medicine and Gerontology. 1994.

33. Chumlea WC, Guo SS, Zeller CM, Reo NV SR. Total body water data for white adults 18 to 64 years of age: the FELS Longitudinal study. Kidney Int. 1999;56:244 52.

34. Sheehy CM, Perry PA CS. Dehydration: Biological Considerations, Age-Related Changes, and Risk Factors in Older Adults. Biol Res Nurs. 1999;1(1):30-7.

35. A M. Senescence of renal cells: molecular basis and clinical implications. Nephrol Dial Transpl. 2003;18:2474-8

36. Phillips PA, Roll BJ, Ledingham JG, Forsling M, Morton J CM. Reduced thirst after water deprivation in helthy elerlymen. N Engl J Med. 1984;311:753-9.

37. Warren JL., Bacon W.E., Harris T., McBean A.M., Foley D.J. PC. The burden and outcomes associated with dehydration among US elderly. Am J Pub Heal. 1994;84:1265-1269.

38. Armstrong-Esther C a, Browne KD, Armstrong-Esther DC, Sander L. The institutionalized elderly: dry to the bone! Int J Nurs Stud [Internet]. 1996 Dec;33(6):619-28. Available from: http://www.ncbi.nlm.nih.gov/pubmed/8970859

39. Hodgkinson. Maintaining oral hydration in older adults: A systematic review. 2003;9(3):19-28

40. Feinsod FM, Levenson SA, Rapp K, Rapp MP, Beechinor E LL. Dehydration in frail, older residents in long-term care facilities. J Am Med Dir Assoc. 2004;5(2):35-41.

41. AC S. Dehydration in the elderly: strategies for prevention and management. Nurse Pract. 1997;22(4):41-72.

42. Rajasoorya C, Holdaway IM, Wrightson P et al. Determinants of clinical outcome and survival in acromegaly. Clin Endocrinol (Oxf). 1994;41:95-102.

43. PM, Gaspar GN. What determines how much patients drink., Geriatr Nurs. 1988;9:221-4

44. Garcia, M.Esperanza GD. Dehydration in the elderly, Nutrition Noteworthy. Nutr Noteworthy, Dep Biol Chem UCLA, David Geffen Sch Med. 2001;

45. RJ L-M. Dehydration in the elderly: A short review! J Natl Med Assoc. 1987;79:1033-8.

46. Lavizzo-Mourey RJ, Johnson J SP. Risk factors for dehydration among elderly nursing home residents. JAmGeriatr Soc. 1988;36:213-8.

47. Carlsson M, Gustafson Y, Eriksson S HL. Body composition in Swedish old people aged 65-69 years, living in residential care facilities. Arch Gerontol Geriatr. 2009;49:98-107.

48. Farrell MJ, Zamarripa F, Shade R et al. Effect of aging on regional cerebral blood flow responses associated with osmotic thirst and its satiation by water drinking: a PET study. PNAS. 2008;105:382-7.

49. Hong X., Janet B. ES. Economical, Burden of Dehydration among elderly hospitalized patients. Am J Heal Pharm. 2004;61.

50. Warren JL, Bacon WE, Haris T, Mcbean AM, Foley DJ, Phillips C. $* \notin-\mathrm{j}\}$ ! _ ] 1991;1265-9.

51. Haveman-Nies A, de Groot LC VSW. Fluid intake of elderly Europeans. J Nutr Heal Aging. 1997;1(3):151-5.

52. Shea AM, Hammill BG, Curtis LH, Szczech L a, Schulman K a. Medical costs of abnormal serum sodium levels. J Am Soc Nephrol [Internet]. 2008 Apr [cited 2014 Jun 4];19(4):764-70. Available from: http://www.pubmedcentral.nih.gov articlerender.fcgi?artid=2390974\& tool=pmcentrez $\&$ rendertype $=$ abstract

53. Glaser R, Naidu SS, Selzer F, Jacobs AK, Laskey WK, Srinivas VS, et al. Factors associated with poorer prognosis for patients undergoing primary percutaneous coronary intervention during off-hours: biology or systems failure? JACC Cardiovasc Interv [Internet]. American College of Cardiology Foundation; 2008 Dec [cited 2014 Apr 29];1(6):681-8. Available from: http://www.pubmedcentral. nih.gov/ articlerender.fcgi? artid=2774122\& tool=pmcentrez\&rendertype $=$ abstract

54. Curtze S, Meretoja A, Mustanoja S, Putaala J, Lindberg T, Leppä M, et al. Does time of day or physician experience affect outcome of acute ischemic stroke patients treated with thrombolysis? A study from Finland. Int J Stroke [Internet]. 2012 Aug [cited 2014 May 16];7(6):511-6. Available from: http://www.ncbi.nlm.nih. gov/ pubmed/22494345

55. P S. The risk of hyponatremia in the elderly compared with younger in the hospital inpatient and outpatient. JIndonesian ournal Intern Med. 2011;13(3):158-61.

56. Sunderam SG M. Hyponatraemia in the elderl,. Review. Age Ageing. 1983;12(1):7780 .

57. JC M. A typology of oral hydration problems exhibited by frail nursing home residents. J Gerontol Nurs. 2006;32(1):13-9.

58. Amin A, Deitelzweig S, Christian R, Friend K, Lin J, Belk K, et al. Evaluation of incremental healthcare resource burden and readmission rates associated with hospitalized hyponatremic patients in the US. J Hosp Med [Internet]. 2012 Oct [cited 2014 Jun 4];7(8):634-9. Available from: http://www.ncbi.nlm.nih.gov/ pubmed/22961813

59. Turgutalp K, Ozhan O, Gok Oguz E, Horoz M, Camsari a, Yilmaz a, et al. Clinical features, outcome and cost of hyponatremia-associated admission and hospitalization in elderly and very elderly patients: a single-center experience in Turkey. Int Urol Nephrol [Internet]. 2013 Feb [cited 2014 Jun 4];45(1):265-73. Available from: http:// www.ncbi.nlm.nih.gov/pubmed/23065433

60. Amin A, Deitelzweig S, Christian R, Friend K, Lin J, Lowe TJ. Healthcare resource burden associated with hyponatremia among patients hospitalized for heart failure in the US. J Med Econ [Internet]. 2013 Jan [cited 2014 Jun 4];16(3):415-20. Available from: http://www.ncbi.nlm.nih.gov/pubmed/23336297

61. Mukand J a, Cai C, Zielinski A, Danish M, Berman J. The effects of dehydration on rehabilitation outcomes of elderly orthopedic patients. Arch Phys Med Rehabil [Internet]. 2003 Jan [cited 2014 Jun 8];84(1):58-61. Available from: http://www. ncbi.nlm.nih.gov/pubmed/12589621

62. Zilberberg MD, Exuzides A, Spalding J, Foreman A, Jones AG, Colby C, et al. Hyponatremia and hospital outcomes among patients with pneumonia: a retrospective cohort study. BMC Pulm Med [Internet]. 2008 Jan [cited 2014 Jun 4];8:16. Available from: http://www.pubmedcentral.nih.gov/articlerender.fcgi?artid=2531075 \&tool $=$ pmcentrez\&rendertype $=$ abstract

63. Zilberberg MD, Exuzides A, Spalding J, Foreman A, Jones AG, Colby C, et al Epidemiology, clinical and economic outcomes of admission hyponatremia among hospitalized patients. Curr Med Res Opin [Internet]. 2008 Jun [cited 2014 Jun 4];24(6):1601-8. Available from: http://www.ncbi.nlm.nih.gov/pubmed/18426691

64. Elixhauser A, Yu K SC et al. Hospitalizations in the United States. , 2000; AHRQ,1997. Rockville, MD Agency Healthc Res Qual AHRQ,1997. 2000;00-0031.

65. 1997 HCUP Nationwide Inpatient Sample (NIS) Design Report [Internet]. Available from: http://www.hcup-us.ahrq.gov/db/nation/nis/reports/NIS_1997_Design_ Report. jsp

66. Chin MH GL. Correlates of major complications or death in patients admitted to the hospital with congestive heart failure. Arch Intern Med [Internet]. 1996;156:1814 20. Available from: http://www.ncbi.nlm.nih.gov/pubmed/8790075.

67. Shorr AF, Tabak YP, Johannes RS, Gupta V, Saltzberg MT, Costanzo MR. Burden of sodium abnormalities in patients hospitalized for heart failure. Congest Heart Fail [Internet]. 2011 [cited 2014 Jun 4];17(1):1-7. Available from: http://www.ncbi .nlm. nih.gov/pubmed/21272220

68. Gheorghiade M, Abraham WT, Albert NM, Gattis Stough W, Greenberg BH, O'Connor CM, et al. Relationship between admission serum sodium concentration and clinical outcomes in patients hospitalized for heart failure: an analysis from the OPTIMIZE-HF registry. Eur Heart J [Internet]. 2007 Apr [cited 2014 Jun 8];28(8):980-8. Available from: http://www.ncbi.nlm.nih.gov/pubmed/17309900

69. Rabinovitz A, Raiszadeh F, Zolty R. Association of hyponatremia and outcomes in pulmonary hypertension. J Card Fail [Internet]. Elsevier Inc; 2013 Aug [cited 2014 Jun 8];19(8):550-6. Available from: http://www.ncbi.nlm.nih.gov/pubmed/23910584

70. Doshi SM, Shah P, Lei X, Lahoti A SA. Hyponatremia in hospitalized cancer patients and its impact on clinical outcomes,. Am J Kidney Dis. 2012;59(2):222-8.

71. Callahan MA1, Do HT, Caplan DW Y-FK. Economic impact of hyponatremia in hospitalized patients: a retrospective cohort study. Postgr Med. 2009;12(2):186-91.

72. Wakefield BJ, Mentes J, Holman JE, Culp K. Risk factors and outcomes associated with hospital admission for dehydration. Rehabil Nurs [Internet]. 2008;33(6):233-41. Available from: http://www.ncbi.nlm.nih.gov/pubmed/19024237

73. Movig KL, Leufkens HG, Lenderink AW EA. Validity of hospital discharge International Classification of Diseases (ICD) codes for identifying patients with hyponatremia,. J Clin Epidemiol. 2003;56:530-5.

74. Waikar SS, Mount DB, Curhan GC. Mortality after hospitalization with mild, moderate, and severe hyponatremia. Am J Med [Internet]. Elsevier Inc.; 2009 Sep [cited 2014 Jun 8];122(9):857-65. Available from: http://www.pubmedcentral.nih .gov/articlerender.fcgi?artid=3033702\&tool=pmcentrez\&rendertype $=$ abstract

75. Hoorn EJ LJ\& ZR. Acute and concomitant deterioration of hyponatremia and renal dysfunction associated with heart and liver failure. Clin Nephrol. 2006;65:248-55.

76. Licata G, Di Pasquale P, Parrinello G, Cardinale A, Scandurra A, Follone G, Argano C, Tuttolomondo A PS. Effects of high dose furosemide and small-volume hypertonic saline solution infusion in comparison with a high dose of furosemide as bolus in refractory congestive heart failure: Long-term effects. Am Hear J. 2003;145:456-66.

77. Leadbetter RA, Shutty MS Jr, Higgins PB PD. Multidisciplinary approach to psychosis, intermittent hyponatremia, and polydipsia. Schizophr Bull. 1994;20:375385 . 